\title{
PIVIEW
}

SEPTEBEER/OCTOBER 1095

Christopher J. Woller is an associate professor of economies at Indianta University and served as a visiting scholar at the Federal Reserve Bank of Si. Lous when this atticte was begun. Stephen M. Stolis provided research assistance. The athor thanks loe Ritter, Ghris Keely, Bill Gavin, carl Woish and Sieve Stohs for their comments on earlier deufts.

\section{Performance Contracts for Central Bankers}

\section{Christopher J. Waller}

\footnotetext{
ince the end of World War II, economies around the world have been plagued by historically high and persistent inflation. This raises a question: If inflation is socially undesirable, why do policymakers produce it? One explanation is that discretionary monetary policy may lead to an inflationary bias. This explanation is based on the "time-inconsistency" problem, first outlined by Kydland and Prescott (1977) and llluminated by Barro and Gordon (1983a). The typical version of this explanation assumes that society wants the monetary authority to follow a low inflation policy, which it promises to do. Once private agents commit themselves to nominal wage contracts based on a low expected inflation rate, however, the monetary authority is assumed to have an incentive to create "surprise" inflation and inflate away the real value of the contracted nominal wage. As a result, firms hire more labor and produce more output. But, because private agents are aware of this incentive, they do not believe that the central bank will carry through with its promise to mantatn inllation at a low level. Hence, workers set their nominal wages high enough so that the extra inflation created by the central bank leaves real wages at their desired levels. Consequently, no additional output or employment is created but society sulfers from at inflation bias.

For the past decade, researchers have investigated an aray of methods with which to reduce this inllation bias. Although most methods promise to lower
}

the inflation bias, they usually do so at the cost of creating greater output variability. However, a recent proposal by Walsh (1995a) and Persson and Tabellini (1993) - the adoption of performance contracts for central bankers-has created a stir among economists working in this area. The purpose of this article is to survey the work on performance contracts and compare it to earlier proposals for mitigating the inflation bias. The remainder of the paper proceeds as follows: The second section contains a model describing the basic time-inconsistency problem and reviews previous suggestions for eliminating the inflationary bias. Following that is a discussion of the nature of performance contracts and how they work. The fourth section probes the principal-agent nature of central banking and its relationship to central bank independence. In the final section, l offer concluding comments.

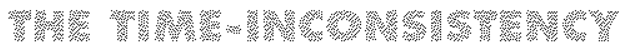

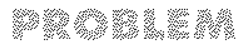

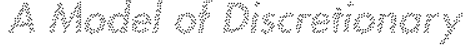

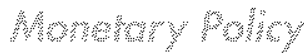

A general description of how monetary policy is determined would go something like this: Society (the principal) delegates the power to create money to the central. bank (the agent). Society instructs the central bank to use its money creation powers to "do good." What is meant by doing good is often not well-defned: nevertheless, it can be interpreted to mean that the central bank should produce a policy that improves the well-being of society. The central bank then enacts policy according to some objective function. Presumably, its objective is to maximize social welfare. but it could also be to maximize something other than society"s welfare. Finally, after policy is enacted, the monetary authority may be asked to account for its actions. 
To illustrate the nature of the timeinconsistency problem, consider the following version of the Barro and Gordon model:

$$
\begin{gathered}
y=y^{n}+\left(\pi-\pi^{e}\right)+u \\
U^{5}=-\left(y-y^{n}-k^{5}\right)^{2}-b \pi \\
U^{M}=w-\left(y-y^{n}-k^{M}\right)^{2}-b \pi^{2},
\end{gathered}
$$

where $y$ is real output, $y^{n}$ is the trend level of output, $\pi$ is the inflation rate, $\pi^{*}$ is the expected inflation rate and $u$ is a mean zero, serially uncorrelated real output shock.

Equation 1 describes how output is influenced by inflation and inflation expectations. Workers are assumed to sign nominal wage contracts prior to the setting of monetary policy and the contracted wage is based on the expected rate of inflation. An inflation surprise reduces the real value of the contracted nominal wage, thereby inducing firms to hire more labor and produce more output

Equation 2 is society's utility function and shows that society suffers from output and inflation fluctuations about their targeted levels. Society's target output level is $y^{n}+k^{5}$, where $y^{n}$ is the natural or trend level of output and $k^{S}$ is a positive constant. The parameter $h^{s}$ is assumed to reflect society's belief that distortions in the economy make trend output undesirably low. Society's preferred inflation rate is assumed to be zero. The parameter $b$ measures the relative weight society places on losses arising from inflation. The weight on losses arising from output has been set equal to 1 for notational ease.

Equation 3 is assumed to be the central banker's objective function. The parameter $w$ is the salary or budget the central banker receives for doing the job. This term is irrelevant in the standard Barro and Gordon model and is usually ignored. But this term plays a key role in the performance-contract literature, so I will include it now for comparison later. Equation 3 looks very much like society's utility function except that the central bank is allowed to have a potentially different output target, $y^{n}+k^{\text {id }}$, than society's. If $k^{m}=k^{s}$, then the central bank's objective is identical to society's. If $k^{M} \neq k^{5}$, then the central bank uses policy to pursue an agenda that is different than that of society as a whole. The reason the central bank has a different agenda is important and is a crucial part of the performance-contract debate, as discussed later in this article. Finally, for ease of analysis, the monetary authority is assumed to control the inflation rate directly and thus chooses $\pi$ to maximize equation 3 given equation 1 .

Consider the case in which the central bank has only society's interests at heart, that is, $k^{\text {k }}=k^{s}=k$. Since society wants inflation to be zero (on average), suppose the central bank can pre-commit to a policy whereby it will not create systematic inflation. This implies that expected inflation is zero. Substituting equation 1 into 3 and maximizing subject to the constraint $k^{\mathrm{M}}=k^{\varsigma}=0$ yields what is called the socially optimal or "pre-commitment" solution for inflation and output:

$$
\pi=-\frac{1}{1+b} u
$$

$$
y=y^{n}+\frac{b}{1+b} u
$$

From equation 4 , the central banker partially offsets the output shock by allowing inflation to vary more. Expected inflation is zero, and expected output is $y^{n}$. In this world, pre-commitment refers to the idea that the central bank can commit itself to making the inflation rate zero on average, but will vary the period-bymeriod inllation rate to stabilize output in a way that maximizes social welfare. The central bank makes no attempt to expand output above the trend level even though it has a desire to do so. In short, even though $k>0$, pre-commitment means the central bank is 
able to credibly promise to act as if $k=0$.

Now suppose that the central bank cannot commit itself to acting as if $k=0$. Now the central banker chooses $\pi$, taking $\pi$ as given, to maximize its objective function. Maximizing equation 3 yields the following expression:

$$
\pi=\left(\frac{1}{1+b}\right)\left(\pi^{c}+k^{M}-u\right)
$$

Rational expectations implies that $\pi^{*}$ must be set consistent with equation 6 . This implies that

$$
\pi^{\circ}=\frac{h^{\mathrm{M}}}{b} \text {. }
$$

which yields the following solutions for the discretionary equilibrium:

$$
\begin{aligned}
& \pi=\frac{k^{M}}{b}-\frac{1}{1+b} u \\
& y=y^{n}+\frac{b}{1+b} u .
\end{aligned}
$$

The only difference between these expressions and those from the pre-commitment solution is that there is now an inflationary bias, given by $k^{* 1 /} b>0$; output is the same.

Why does the inflation bias arise? Because the target level of output is higher than the trend value. Once wage contracts are signed, the central bank can increase output above trend by creating an inflation surprise. The central bank does this not out of self-interest but because society wants it to. Even though society as a whole desires this, however, individual agents have no incentive to allow their wages to be inflated away. Consequently, they set expectations and nominal wage demands accordingly. In equilibrium, the economy suffers from excessive inflation with no additional gains in output. It can be shown that the loss from the discretionary equilibrium is higher than it would be in the pre-commitment case. Thus, even though the central banker does what society wants him to do, the use of discretionary policy makes society worse ofl in equilibrium.

There are three points to note about equations 8 and 9 . First, the inflation bias is a constant-it is not a random variable nor does it vary over lime. Second, the bias does not depend on the output shock. Third, the stabilization response to the output shock $u$ is the same in both the socially optimal solution and the discretionary solution. These features all come into play when discussing the optimal design of performance contracts.

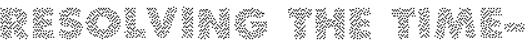

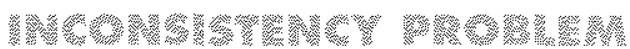

Since the publication of the Barro and Gordon (1983a) paper, research has focused on ways of eliminating this inflationary bias. There have been two distinct directions of research: the reputationbuilding approach and the institutionaldesign approach.

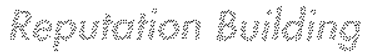

The reputation-building approach focuses on the use of "punishment" strategies by private agents to deter the central bank from generating the inflation bias. In these models, workers believe the central bank will follow a low inflation policy as long as it has not tried to surprise workers in the past. Otherwise, they "punish" the central bank by expecting a high inflation rate, which the central bark validates to avoid creating a recession. By using this type of mechanism, the private sector is able to persuade the central banker to develop a reputation for enacting the announced policy. Barro and Gordon (1983b) showed that reputation building would generate a lower inflation bias but wottd not eliminate it.

Barro and Gordon's early model of reputation was done under the assumption of perlect information. Subsequent research examined how robust the reputation- 
building approach was to information imperfections. Canzoneri (1985) showed that the economy would suffer inflation "cycles" due to occasional breakdowns in credibility if private agents were unable to separate exogenous inflation shocks from systematic policy actions. Backus and Driffill (1985), Barro (1986) and Rogoff (1987) showed that if private agents are unsure of the central banker's type-inflation hawk or dove-then a recession will frequently occur early in a central banker's term. This is because private agents' expectations of inflation are an average of the hawk's and the dove's equilibrium inlation rates. If the central banker is a hawk, inflation is set lower than expected and a recession occurs. If the central banker is a dove, he may act tike a hawk and create a recession to build a reputation as a hawk. The reason is that if the dove inflates immediately, he reveals himself as a dove and inflation expectations will be higher for the remainder of his term in office. By acting like a hawk, he manages to keep inflation expectations low. The dove, however, eventually chooses to create an inflation surprise and expand output for a short period of time. Thus, while inflation is lower on average, output and inflation are more variable.

Although reputation models are able to generate lower equilibrium inflation rates, albeit at some cost of greater output variability, they have several unappealing aspects. First, there are an infinite number of punishment strategies that conld be adopted, and it is not obvious which is the correct one to use. For example, how long should the punishment last?

Second, the multiplicity of strategies suggests that private agents would have to coordinate their actions to send a clear signal to the central bank as to how they would behave in the event that they are surprised. But how is such coordination to be achieved? I arge, national trade unions may be sufficient for coordinating actions in some countries, but this is not a feasible solution in the relatively atomistic labor markets that characterize the U.S. economy.
Third, the reputation approach tends to focus on the personality and reputation of individual central bankers. Because individuals do not serve as the central banker for long periods in the real world, this approach suggests that there will be considerable uncertainty and variability of policy as central bankers turn over. Thus, we should focus on ways of developing the institutional reputation of the central bank instead of the reputation of individual central bankers.

Finally, the reliance on the private sector to enforce the appropriate path of monetary policy is a bit unpleasant from a public policy perspective. The reputationbuilding approach does not try to change the central bank's objective function directly; rather, it alters the central bank's behavior by making the policy choice dynamic, that is, by making today's policy actions have future consequences. But if the institutional structure of the central bank provides it with the wrong policy incentives, then it would seem prudent to change the institution rather than rely on private agents to solve the problem.

To illustrate this point, consider the response to airline hijackings. One way of dealing with hijackers is to arm the passengers and let them enforce peace on the airplane. This is akin to what the reputation approach does for the inflation bias. A better idea is to change the environment for boarding a plane so that the likelihood of a hijacking is reduced - hence, the use of metal detectors.

As a result of these problems with the reputation-based approach, researchers began to investigate institutional reforms for the central bank that would mitigate the inflationary bias.

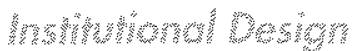

The institutional-design approach focuses on using legislative means to restrain the central bank from engaging in high-inflation policies. The intent is to manipulate the central bank's objective function directly through legislative action. Some work in this area has 
focused on legislation that restricts the day-to-day operating procedures of the central bank; other research shows how the appointment process for central bankers can be used to elicit better inflation performance. Advocates of the latter line of research recommend making the cenrral bank independent from elected leaders as a means of reducing the inflationary bias.

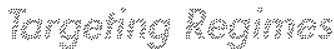

Legislative restrictions on the central bank often take the form of imposing monetary targeting or adopting simple rules (which are actually targeting regimes with a horizon of one period). The adopm tion of Friedmanesque k-percent rules has been studied by Alesina (1988) and Lohmann (1992). They show that these rules eliminate not only the inflationary bias, but also stabilization of output by the monetary authority. Hence, there is a trade-off between reducing inflation and stabilizing output. Simple rules dominate discretion when output shocks are small and relatively rare. ${ }^{3}$

Multi-period targeting horizons have been examined by Canzoneri (1985) and Garfinkel and on (1993). In these models, the central bank must follow policies so that the targeted inflation rate occurs on average over some time interval. In this environment, the central bank creates an inflation bias early in the targeting horizon, but it is smaller than it would have been in the absence of targeting. However, it produces sub-optimally low inflation (or even deflation) at the end of the targeting horizon to bit the targeted inflation or money growth rate. Stabilization is also sacrificed in the name of inflation, since shocks early in the period are not stabilized in an optimal fashion because those actions must be reversed later in the targeting period.

An implicit assumption in these targeting models is that the central banker's worst penalty for missing the target is dismissal (shooting him is not a realistic punishment). Consequently, the central banker's self-interest plays a large but hidden role in these types of models.

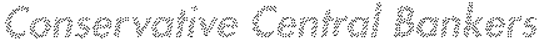

The appointment and reappointment of a central banker who sets policy according to his own self-interest plays a large role in other institutional schemes for dealing with the inflation bias. Thompson (1981) and Rogoff (1985) proposed appointing a "conservative" central banker who dislikes inflation more than everyone else in society. A conservative central banker generates a lower inflationary bias but does so by not stabilizing the economy in a socially optimal fashion.? To illustrate this point, suppose that society appoints a central banker who puts more weight on inflation than it does. The central banker would then have a larger value of the parameter $b$ in equation 3 to use in setting policy. From equations 8 and 9 , however. we see that a larger value of $b$ reduces the inflation bias but makes output more variable.

For the conservative central banker's policies to be credible, society must believe that he cannot be removed ex post by the current government. Thus, the central banker must have some degree of independence to pursue policies that are not desired by the current administration (and, implicitly, the electorate). Subsequent research by flood and lzard (1989) and Lohmann (1992) showed that complete independence was not socially optimatfor certain bad states of the world, society benefits from firing the conservative central banker and stabilizing output.

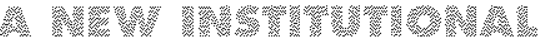

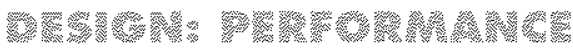

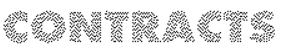

A consistent theme of both the reputation-building and institutional-design models is that the inflation bias can be reduced or eliminated, but usually at the cost of having the central bank reduce its
1 Recently, Houbidich and Riter (1995) howe agued that this romperison between sirnole Ithes and discretion is biased in foroo of rules, becouse it assumes that the thoice between adopting a simple rule over discetion is on one-time decisicien. In tact, menetay autionity has the ention of writing before combitting to a k-percent rule, and this option has value thot is typically ignoed in the Alesing ond Lohnumn anclyses. Thus, they argue that discretion is nore likely to be prefered thon is sypicully shown.

2 Foust (1994) has shown that the appoietment of a centrol bonker who patefers a lowes frend inflotion rote thon the meditan voles con impove socicl welfare if the majority of waters ore net nominal debt holders. Stablitution issues, howere, ore not stutied in Fraust's moddel. 
emphasis on stabilizing output. Thus, there appears to be a trade-off between reducing average inflation and stabilizing the real economy.' Debate has centered on the relative benefits and costs of this tradeoff in determining the goals of monetary policy, and the types of legislative restraints to place on the central bank.

Recently, however, a new idea has surfaced in the institutional-design literature for dealing with the inflation bias. The idea is to offer the central banker a performance contract, whereby the central banker's salary or the bank's budget is tied directly to the performance of important macroeconomic variables such as GDP and the inflation rate. By giving the central banker the proper financial incentives, these researchers have shown that the central bank can be induced to generate low inflation without forsaking its stabilization responsibilities.

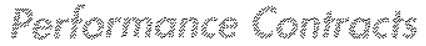

Walsh (1995a) suggested that the monetary policy game be viewed as a principalagent problem. ${ }^{+}$In a principal-agent model, one individual or group (the principal) delegates control over a policy variable to another individual or group the agent). Although the principal would tike the agent to set policy so that the princi-

3 Enplivical evidence on this point is mixed. For exarnple, some resecthors hawe shown that grenter contral bank incigendence is assodated with lower avergge intlation rates bot hos no relotionship with the var ance of GOP. Other wot hos shown that countries with independent central bonks iend to suffer greater output losses dur ing disintlotions, which surggests that there is a tade-off beween educing intotion and stobilizing output verichilly.

4 Persson and Tabellinis (1993), woking from an enty troft of Woish's poper, extended his mppooch to a moes gerend fromework. pal's welfare is maximized, the agent has a different objective and opts for a policy that does not give the principal its most desired outcome. The solution to this problem is for the principal to offer the agent a contract that gives the agent the incentives to enact the policy desired by the principal.

By viewing monetary policy as a principal-agent model, Walsh redirected attention to the source of the problem-the central banker is confronted with a set of preferences that do not yield the outcome that society prefers most. So rather than worry about appointing conservative central bankers or adopting appropriate reputation strategies, Walsh argued that we should provide the central banker with the incentives to "do the right thing"-even if those incentives do not appear, at first glance, to be consistent with maximizing society's well-being. The problem is determining what those incentives should be.

Following the principal-agent literature, Walsh proposed offering the central bank a performance contract. This contract ties the central banker's personal compensation or the size of the bank's budget to the performance of the economy. Once the contract is signed, society encourages the central banker to pursue his own self-interest and adopt policies that increase his income or the bank's budget. The trick is to structure the contract in such a way that by trying to increase his own resources, the central banker maximizes social wellare in the process.

This approach is a radically different way to deal with policymakers. Under this institutional design, society exploits the pursuit of self-interest by the central banker to achieve the socially desirable outcome. This differs from the traditional view of appointing a benevolent central banker and then instructing him to do good. Under the performance contract approach, society essentially says: "You can do what you want, but you will pay personally for undesirable outcomes." Making the central bank accountable for its actions is a prominent theme of performance contracts.

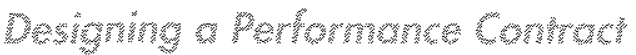

What does a performance contract look like? Consider the following compensation contract for setting the central banker's salary ( $w$ in equation 3 ):

$$
w=s-\hat{\lambda} \pi
$$

where $s$ denotes the central banker's base salary or the budget of the central bank. This contract specifies that the central banker be paid a base salarys, which will be reduced if any inflation occurs. The degree of salary reduction is determined by the parameter $\lambda$. A key leature of this contract is that it is based solely on the publicly observed inflation rate; it is not based 
on items that are unverifiable (such as how hard the central banker works).

Once the contract is in place, society tells the central banker to set policy in any manner he sees fit; there is no mention of pursuing the public good. Therefore, given equations 1,3 and 10 , the central banker chooses $\pi$ to maximize

$$
U^{i n}=s-\lambda \pi-\left(y-y^{4}-k^{4}\right)^{2}-b \pi^{2}
$$

This yields the following expression for the inflation rate:

$$
\pi=\left(\frac{1}{1+b}\right)\left[k^{k}+\pi^{e}-\lambda-u\right]
$$

Imposing rational expectations yields the following equilibrium solutions for inflation and output:

$$
\begin{aligned}
& \pi=\frac{k^{M}-\lambda}{b}-\frac{1}{1+b} u \\
& y=y^{n}+\frac{b}{1+b} u .
\end{aligned}
$$

Given these expressions for what inflation and output will be when the central banker pursues his own self-interest, society would like to set the weight $\lambda$ such that the expressions in 13 and 14 are exactly the same as those given by the precommitment solutions in equations 4 and 5. This result can be accomplished by setting:

$$
\lambda=k^{M} .
$$

By selting $\lambda=k^{*}$, the reduction in salary from creating an inflation surprise just offsets any benefits that would accrue from expanding output towards $y^{\prime \prime}+k^{3}$. Hence, on the margin, the loss of income for the central banker is just equal to the utility gain from creating surprise inflation and expanding output, so he chooses not to create surprise inflation and no inflation bias occurs.
Furthermore, output and inflation are stabilized in the socially optimal fashion. The reason this can be accomplished is that the inflation bias is constant and independent of the output shock $u$. So a simple linear penalty for inflation is sufficient to deter the central bank from inflating. But the key point is that eliminating the inflation bias through appropriate incentives does not require the central banker's stabilization response to be distorted. Therefore, there is no cost for eliminating the inflation bias. By careful construction of the central banker's compensation, society is able to eliminate the inflation bias and have output optimally stabilized. This is indeed a pleasant result.

The contract could take a variety of different forms and still generate the optimal outcome. Every contract, however, must have the feature that the central bank pays more attention to inflation (or less attention to output) than society does. This simply reflects Rogoff's (1985) notion of a conservative central banker. The only difference is that in Rogoff's framework, society carefully selects a central banker who has the "right" personal attributes to reduce inflation, whereas the contract approach gives any arbitrarily chosen central banker the appropriate incentives to produce low inflation. In general, the principle of Rogolf's idea is still relevant; the issue is how to define "conservative."

Rogoff's definition of a conservative central banker was someone who put more weight on inflation relative to stable output. But we could define a conservative central banker as someone who has a lower inflation rate tatget or lower output target than the rest of society. In all cases, the central banker cares relatively more. about inflation than output.

For example, consider the following performance contract:

$$
w=s-2 k^{M}\left(y-y^{n}\right)+\left(k^{M}\right)^{2} .
$$

In this example, society simply offers the central banker a contract that penalizes him if output is above the natural tate. plus adds a fixed amount to the base salary 
according to the magnitude of $k^{m}$. Substituting 16 into 3 and rearranging yields

$$
U^{\mathrm{M}}=s-\left(y-y^{n}\right)^{2}-b \pi^{2} .
$$

The contract in 16 leads to an objective function for the central banker that is equivalent to appointing a central banker with a lower output target than the rest of society, since the parameter $k^{m}$ disappears. With this contract the central banker will use discretion to produce the socially optimal outcome.

Alternatively, Svensson (1995) proposes a contract of the form:

$$
w=s+2 b \pi^{c} \pi-b\left(\pi^{c}\right)^{2},
$$

where $\pi^{\circ}$ is an arbitrary constant to be determined by society. Substituting 18 into 3 and rearranging yields

$$
U^{M}=s-\left(y-y^{n}-k^{M}\right)^{2}-b\left(\pi-\pi^{c}\right)^{2}
$$

If $k^{*}=k^{s}$, this contract looks very much like society's utility function except that the central banker's target inflation rate is now different from zero. Thus, the contract in 18 is observationally equivalent to appointing a central banker with a different inflation target than the rest of society's. A central banker with this contract will set policy such that, in equilibrium, inflation and output are given by

$$
\begin{aligned}
& \pi=\frac{k^{M}}{b}+\pi^{c}-\frac{1}{1+b} u \\
& y=y^{n}+\frac{b}{1+b} u .
\end{aligned}
$$

Notice that in setting $\pi^{5}=-k^{3} / b$, we obtan the socially optimal solution. Thus, by having the central banker target a desired inflation rate of minus the inflation bias, society obtains its most preferred out- come. Because the central banker's targeted inllation rate is less than society's preferred rate, the central banker appears more conservative than the rest of society; in contrast to Rogoff's model, however, this type of conservative central banker does not cause stabilization to be sub-optimal.

The key point of this discussion is that offering the central banker a performance contract may be equivalent to appointing an appropriately defined conservative central banker. Once we realize this, there is no reason to believe that these central bankers will understabilize the economy.

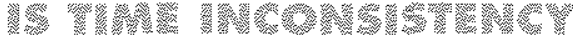

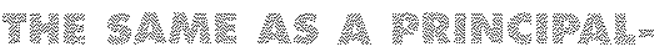

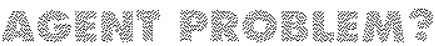

In the performance contract approach above, it was shown that appropriately chosen contracts can induce the central banker to produce the socially optimal. outcome. This result was demonstrated without any reliance on the assumption that the central banker's output target was equal to society's. Walsh conducts his analysis under the assumpion that society and the central banker have the same objective functions, that is, $k^{3 / 4}=k^{s}$. This assumption is common in the time-inconsistency literature, but is not consistent with the principal-agent model. Usually in a principal-agent problem, the agent has a different objective than the principal. A more classical depiction of the principalagent problem would look like the following utility functions:

$$
\begin{gathered}
U^{S}=-\left(y-y^{n}\right)^{2}-b \pi^{2} \\
U^{M}=w-\left(y-y^{n}-k^{M}\right)^{2}-b \pi^{2} .
\end{gathered}
$$

With this formulation, society has preferences that are consistent with the socially optimal solution given in 4 and 5 . The central bank, on the other hand, wants 
output to be higher than its trend valuc (for some unspecified reason). Thus, the central banker uses his discretionary powers to create an inflation surprise, thereby expanding output. Rational agents foresee this and adjust wages so that they are not fooled. The outcome is an inflation bias with no additional output gains.

Although the story is the same as the time-inconsistency model described above, there is one fundamental difference: Society does not want the central bank to try to expand output above trend. The central bank does so in pursuit of its own self-interest. This situation is what performance contracts were designed for: enticing a "misbehaving" agent to produce the principal's desired policy.

But if the petformance contract generates the socially optimal outcome regardless of whether society and the central banker have the same output targets, why is it important to classify the problem as a time-inconsistency problem rather than a principal-agent problem? The reason is that if the policy game is described as the principal-agent problem as in equations 22 and 23 above, the credibility of contract enforcement is not an issue. The principal very clearly wants the socially optimal policy to be implemented and has every incentive to hold the central banker to the contract and not renegotiate it. But in the case in which the central banker is trying to give society what it wants, society is inconsistent-it wants higher output, which can only be achieved by being "fooled;" yet, society does not want to be fooled. If the central banker is maximizing social wellare, then society should renege on the performance contract once private agents set their wages -it should let itself be fooled. Since it is optimal ex post to renege on the performance contract, then private agents will never believe it changes the central banker's incentives, and we are right back where we started.

The credibility of contract enforcement raises an important point: Timeinconsistency and principal-agent relationships are not the same thing, even though performance contracts appear to solve both types of problems. Thus, one needs to be careful in using solution concepts interchangeably.

Enforceability of the performance contract corresponds to McCallum's (1995) second fallacy of central bank independence. McCallum argues that a performance contract "does not actually overcome the motivation for dynamic inconsistency; it merely relocates it" (p. 210). As long as the central banker is presumed to be maximizing social welfare, this argument is correct. But if the inflation bias is actually the result of a "true" principalagent problem rather than a time-inconsistency problem, society can pre-commit itself to enforcing the contract.

Actually, McCallum's criticism of performance contracts is too strong. While it is correct to say that a perfect commitment technology or institutional design does not exist (for example, even the U.S. Constitution is not a perfect commitment to liberty because we can change it anytime we want), it is possible to make the costs of reneging on promises more costly and thus make monetary policy more credible. The basic idea of performance contracts, and the premise behind the entire institutional-design literature, is to increase the cost of reneging on a cooperative arrangement. Some institutions have low reneging costs (a policy target), while others have very high reneging costs (abolishing the Fed). By relocating the source of dynamic consistency, performance contracts attempt to increase the costs of reneging on low inflation promises.

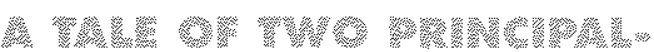

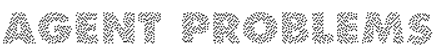

In equations 22 and 23 , the central banker has different objectives than society as a whole in that he wants to increase output above the current trend value. This mathematical form corresponds to the traditional principal-agent problem. But why would the central bank have an objective 
that differs from what society wants?

The answer to this question lies in the policy structure of most democracies. The general public elects a leader who either conducts policy himself or delegates the control of policy to someone else. Monetary policy typically falls in the delegation category. In the United States, for example, voters elect the President and members of Congress who, in turn, delegate the control of monetary policy to the Federal Reserve. Although they delegate control of monetary policy, the President and the Senate jointly determine who shall serve as the head of the Federal Reserve. Thus, there are typically three actors in any monetary policy model: the voters, the elected leaders and the central banker. In the time-inconsistency model, all of these actors are assumed to have the same objective. From a principal-agent perspective, however, the presumption is that they have differing objectives.

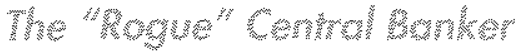

Consider the following principal-agent problem. The voters and elected leaders have the same policy objective, given by equation 22, while the central banker has the objective function given in 23 . In this case, the central banker is a "rogue" policymaker who sets policy to maximize his self-interest rather than society's or the elected leaders' and who, by doing so, creates an inflation bias.

Why would the central bank behave this way? Central bankers may want to maximize their amenities such as the number of staff members, the luxuriance of buildings and the size of travel budgets, all of which are funded by excessive seigniorage creation." Or if the central bank is unduly influenced by a special interest group, say the banking/financial sector, it may pursue policies that benefit these sectors rather than society. Regardless of the source of the problem, performance contracts are a desirable way of dealing with it. Society and the elected leaders use a performance contract to rein in the central banker and make him accountable to the electorate (why elected leaders do not simply take control of monetary policy then is somewhat puzzling).

According to this scenario, central bank independence is an undesirable institutional structure. The performance contract approach can work only if the elected leaders have control over the central bank through the setting of budgets and salaries, and the ability to dismiss the central banker over policy actions. For example, Walsh (forthcoming) shows that if adjusting the bank's budget and salaries is infeasible, then threatening to dismiss the central banker if certain poor policy outcomes arise can replicate the equilibria supported by performance contracts. Walsh refers to these optimally designed threats as "dismissal contracts," since the central banker knows exactly which conditions will lead to his dismissal and agrees to such an arrangement.

The implications for central bank independence in this setting are very different from what is generally thought to be. Central bank independence is generally believed to be a crucial element of good inflation performance, and the empirical evidence to date is consistent with that view (see Alesina and Summers, 1993). Because of this theoretical and empirical evidence, legislation has been introduced around the world that aims at increasing the independence of central banks.

Why do the implications for central bank independence forthcoming from the principal-agent story described above differ so much from what is actually happening in the world? A likely explanation is that this principal-agent story is not the correct view.

\section{Eleved Leaters A Monetary Auhority}

Consider an alternative principalagent problem proposed by Fratianni, von Hagen and Waller (1995). Suppose that voters face an agency problem with elected leaders. Voters want leaders to carry out policies consistent with their objective function in equation 22 , but leaders may ouput torget 
have incentives to misuse monetary policy for political reasons. For example, elected leaders may follow policies that benefit. special interest groups or that further their short-run re-election chances. If unusually high levels of output increase an incumbent's chances of being re-elected, he may try to create surprise inflation to expand output above trend. Furthermore, significant partisanship in the policy process may lead to a redistribution of resources that does not promote the public good. These are all reasons the elected leaders may have an objective function similar to equation 23, if they controlled monetary policy directly.

If elected leaders have an incentive to misuse monetary policy, it is in society's interest to delegate policy to a non-political agent who will enact the policies desired by the general public. This agent would have society's objective function as his own. The problem is: How is this non-political agent chosen? Elections will not work since getting re-elected may be why policy is misused in the first place. The central banker needs to be appointed, but this is typically done by the elected leaders. ${ }^{6}$ Thus, elected leaders can use appointment or the threat of non-reappointment to pressure the central bank into implementing policies aimed at helping the incumbent leaders. If the central bank's budget or the central bankers' salaries are under legislative control, then the central bankers can be pressured through budgetary cuts to pursue sub-optimal policies.

In this framework, the central bank would like to do the right thing but its immediate principal-the elected leaders-have objectives that differ from the general public. The elected leaders, not the central bank, need to be made accountable. Accordingly, society benefits by making the central bank as free of political interference as possible, since inflation will be reduced and output will be stabilized optimally. Thus, central bank independence is crucial for good monetary policy; without it, the central bank is merely a veil for political leaders. Anything that makes the central banker's appointment and budget less susceptible to political pressure will lead to better monetary policy. This view of the principal-agent nature of monetary policy has led academic economists to support the movement toward greater central bank independence.

What would be the purpose of central bank performance contracts in this latter version of the principal-agent problem? If the elected leaders are the ones who write and enforce the central bank's performance contract, then they probably will not solve the problem. Clearly, enforcement of the contracts would lack credibility since elected leaders have an incentive to forgive any transgressions the central bank makes (as long as the transgressions benefit the elected leaders).

There is one potential benefit of using performance contracts in this environment. Performance contracis make policy more visible and the goals of the monetary authority more transparent. Presumably, this visibility would lead to better policy actions, since deviations from the socially optimal path would have to be explained publicly at specified intervals of time. Individuals who employ political pressure on the central bank would be brought into the public limelight and the personal costs to elected leaders from this attention, we hope, would deter them from putting pressure on the central bank. Furthermore, although it is a blunt instrument, the ballot box may provide enough credibility in the enforcement of the contract such that better macroeconomic performance would be achieved.

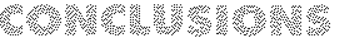

Although theoretically appealing, performance contracts may not be feasible in practice. In fact, political infeasibility may well be the reason we do not observe this type of institutional arrangement in the real world. Nevertheless, the performance contract research we see today could well turn out to be the foundation for the design of central banks in the 21st century. But we'll need to try a few experiments first to see how well they work in practice. New Zealand's recent reforms of its central
6 The interested render sheuld see Woller $(1992,1995)$ for an example of such on appoint ment process.

7 Woller (\$992, 1995), Wolle: and Wolsh (7995) and hesina and Gatti (1995) show how reducing the degres of political influence in the appeintment process ant lead to superion mncroeconomic outcomes. 
bank structure seem to be very similar to a performance contract and may well be the test case we need. Evidence to date is sparse, but the reforms appear to have played a role in reducing inflation and inflation expectations.

Future designs of central bank institutions will probably reflect a combination of independence and performance contracts. The result would be highly autonomous central banks that are clearly held accountable to the electorate. What more could we ask for?

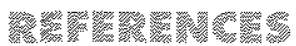

Alesind, A A- Herto. "Alternative Monetary Regimes: A Review Essay," Jound of Honetory Economics (1988), pp. 175-84. and Roberto Gatti. "Independent Central Bronks: Low Inflation at No Cost?" Americon Fronomic Review Papers and Proceedings (1995), pp. 196200.

and Lowence Summers. "Contral Bonk tadependence and Mocroeconomic Pefformance: Some Componative Evidence," Joumol of Money, Gredit, and Banking (1993), pp. 151-62.

Bockus, Dowd, and lohn Driffill. "Inflotion and Reputation," The Americon Economit Review (1985), op. 530-38.

Barro, Robert J. "Reputation in a Model of Monetary Policy with Inconplete Information," Joumal of Monetary Economics (1986), pp. 120.

and Dovid B. Gordon. "A Positive Theory of Monetary Policy in a Notural Rote Hodel, "Jound af Polificol Econony (1983a), pp. $589-610$.

and "Rutes, Discretion and Reputution in a Motel of Monetay Policy" Jound of Monefory Economics (1983b), pp. 101-22.

Conzoneri, Mathew. "Monetary Policy Games and the Role of Privote Information," The Americon Economic Review (1985), sp. 1056-70.

Faust, Jon. "Whon Can We Trust to Run the Fed: Theoretical Support for the Founders' Views," working poper (1994).

Frofionti, Michete, Jugen von Hagen and Gristopher J. Woller, "Centrol Bonking os o Peliticat Pincinol-Agent Problem, "Economic inguiry (fortheoming).

Food, Robert, and Peter lzoud. "Monetory Policy 5trategies," Internotiond Monetury Fund Staff Popers (1989), pp. 61232.

Gorfinkel, Mithelle, and Seonghwon oh. "Strategic Discipline in Monetary Policy with Pivate Information: Opting Targeting Hoizons," The American Economic Review (1993), pp. 99-117.

8 See Hutchison (1995) and Spiegel (1995)
Haubrich, Joseph, and loseph Ritter. "Oynomic Commitment and Imperfect Policy Rules, "Federal Resefve Bunk of St. Lous Working Paper No. 95015 (November 1995).
Hutchison, Michoel. "Centrol Bank Ceedibility and Disinillation in New Zeotond, "Federal Reserve Bonk of San Fruncisco Weekly Letter (Fetrucul 1995).

Kydland, Finn, and Edword Prescott. "Rules Rother Than Discretion; The Inconsistency of Optimal Plans," Joumal of Polfical Econony (1977), po. 473.92 .

Lohmonn, Susonne. "Optimal Commitment in Monetory Policy: Gedibitity Versus Flexiblity," The American Economic Review (1992), pp. 27386 .

McCallum, Bennett. "Two Fallaces Concerning Central Bank Independence," The Americon Fronomic Review Popers and Proceedings (1995), pp. 207-11.

Perssen, Torsten, and Guilo Tobellini. "Designing Institutions for Monetary Stobility" Comegie-Rochester Conference Series on Public Policy (1993). pp. 55-83.

Rogoff, Kenneth. "Repttotiond Construins on Honetary Policy," Contegie-Bochestar Conferente Series on Public Policy (1987), pp. 141-82.

"The Optimel Degree of Commitment to on Intermedlate Target," Qunterly Jountal of Economics (1985), pp. 1169-90.

Spiegel, Mokk. "Rules ws. Discretion in New Zeolond Monetory Policy" Federol Reserve Bonk of San Francisco Weekly Lefter (March 1995)

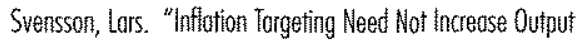
Vorobility: Comment an Rogoff and Wolsh, "woking poper (1995), Institute for Internatienal Economic Studies, Stakkholn Uniwersity.

Thompson, Forl. "Who Should Control the Maney Supply" The American Economic Review Papers and Proceedings (1981), pp. 35661 .

Woller, Christopher I. "Appointing the Medion Votes to o Policy Board," working peper (1995)

"A Bargaining Maddel of Portisan Appointments to the Centrdat Bonk," Journol of Monetory Economics (1992).

and Corl E. Wash. "Central Bank Independence, Economic Behovior, and Optimal Term Lefghth," working paper (1995).

Walsh, Cal E. "Is New Zealand's Reserve Butak Act of 1989 on Optimat Central Bonk Controct?" Joumal of Money, Credit, and Bonking (forthcoming).

"Optenal Controcts for Centiol Bankers," The Americon Economic Review (1995), pp. 150-67.

"When Should Centrol Bonkers Be Fired?" wokkng poper (September 1994), Universify of Califorina of Santa Crezz. 